\title{
Eduardo Lourenço: Amigo dos poetas
}

por Paola Poma e Fernando Ribeiro

Resumo: Entrevista com Eduardo Lourenço no dia 5 julho 2018 - referente ao lançamento de Fernando Pessoa Revisitado, Brasil /Editora Tinta da China - realizada pela Professora Doutora Paola Poma da Universidade de São Paulo e pelo Professor Doutor Fernando Ribeiro da Universidade Nova de Lisboa na Fundação Calouste Gulbenkian, em Lisboa.

Palavras-chave: poesia, crítica, Fernando Pessoa

\section{Eduardo Lourenço: Friend of the poets}

Abstract: Interview with Eduardo Lourenço on July 5, 2018 - in reference to the launch of Fernando Pessoa Revisitado, Brazil/ Ed. Tinta da China - by the Prof. Dra. Paola Poma, from Universidade de São Paulo, and by Prof. Dr. Fernando Ribeiro, from Universidade Nova de Lisboa. The interview was done in Calouste Gulbenkian Fondation.

Keywords: poetry, criticism, Fernando Pessoa

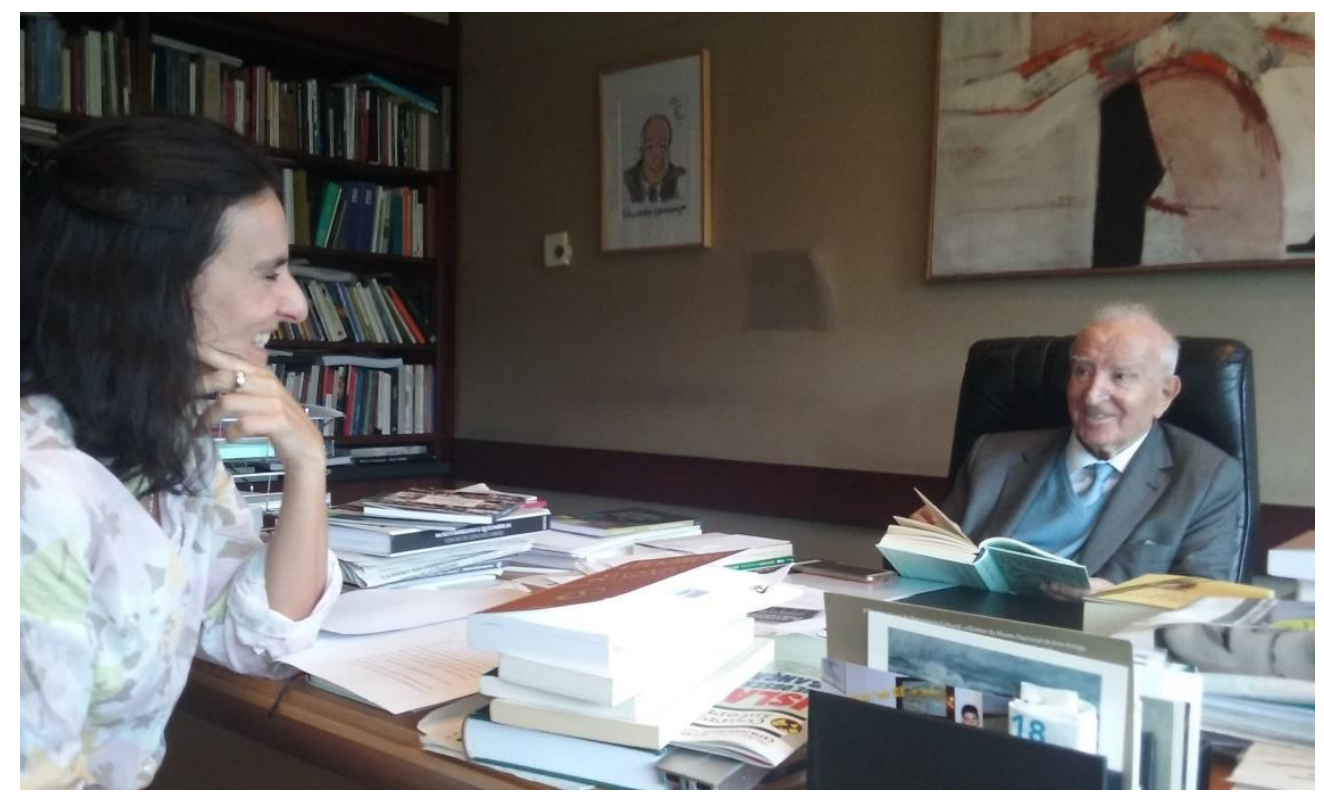

PP: Acaba de sair pela Tinta da China-Brasil o livro Pessoa Revisitado (PR), obra publicada pelo Professor em 1973. Obra de crítica maior sobre a arte poética de Fernando Pessoa escrita com paixão. Ensaísmo e paixão caminham juntos?

EL: Não são incompatíveis, mas neste caso não sei se posso chamar paixão ao fato de, em certa altura da minha vida, ter encontrado em meu caminho um poeta que ia modificar, e muito, a minha visão das coisas por se tratar de figura incontornável da cultura portuguesa, 
i.e., figura principal da ordem poética realmente esperada desde a morte de Camões. Não é que não existam poetas famosos em Portugal, a começar pelo irmão mais novo Mário de Sá Carneiro, que foi a minha primeira adoração. Ainda hoje penso tratar-se de um dos grandes poetas portugueses detentor até de uma espécie de fulgurância de um tipo mais modernista propriamente dito que a de Fernando Pessoa. O Pessoa é sempre ele e o contrário dele. E o Sá-Carneiro é uma espécie de fogo que queima tudo onde passa, acabando ele próprio por arder.

Interessante ocorra agora no Brasil uma edição do Fernando Pessoa Revisitado. O Brasil é o espaço paradisíaco, virtual da nossa cultura enquanto cultura portuguesa e ao mesmo tempo brasileira - o mesmo acontecendo com todos os países, nos quais Portugal deixou o traço da sua língua. Tornou-se uma espécie de ícone cultural da lusitanidade ou de portugalidade se quiser. Hoje estou convencido que terá ainda mais vida do que em Portugal, i.e., será ainda maior o interesse, como se tivesse acabado de ser lançado em primeira mão no Brasil. Em Portugal, a certa altura dizia-se "Tanto Pessoa até enjoa". A mim nunca enjoou.

PP: Então é paixão feliz?

EL: Não é Pessoa que enjoa, somos nós que temos de estar atentos ao que representava para ele o enjoo: a crítica mais radical da condição humana e das suas contradições insolúveis e insanáveis. Isso é normal. De resto, o Brasil tem grandes cultores de Fernando Pessoa como a minha madrinha Cleonice Berardinelli, Leyla Perrone Moisés, Maria Helena Nery Garcez. O Brasil deve ser o país onde Pessoa ainda é vivo e objeto de teses contínuas, recensões, ensaios, etc. O Brasil foi o país para onde enviou um dos heterônimos...

PP: Ricardo Reis

EL: Curiosamente o heterônimo que suscitou uma releitura diferente do Fernando Pessoa enquanto ortônimo e, sobretudo, teve muita sorte porque um dos nossos escritores conhecidos e prêmio Nobel é um seu fã.

PP: José Saramago (O Ano da morte de Ricardo Reis)

EL: De todo modo Pessoa não precisa de acólitos, vive no seu paraíso de solitude. Não sei, não estou na cabeça dele, ninguém está, a cabeça dele é que está por nossa conta.

FR: Essa a originalidade em Eduardo Lourenço exegeta: mergulhe-se dentro de FP; ao exegeta o grande respeito pelo gênio. 
EL: Foi um pouco esse o ponto de vista da ordem crítica. Os poetas é que têm de nos convencer, de existir ou de não existir para nós. São uma espécie de luz que se encontra ou de fogo que nos queima, ou então é um exercício puramente retórico e sem interesse.

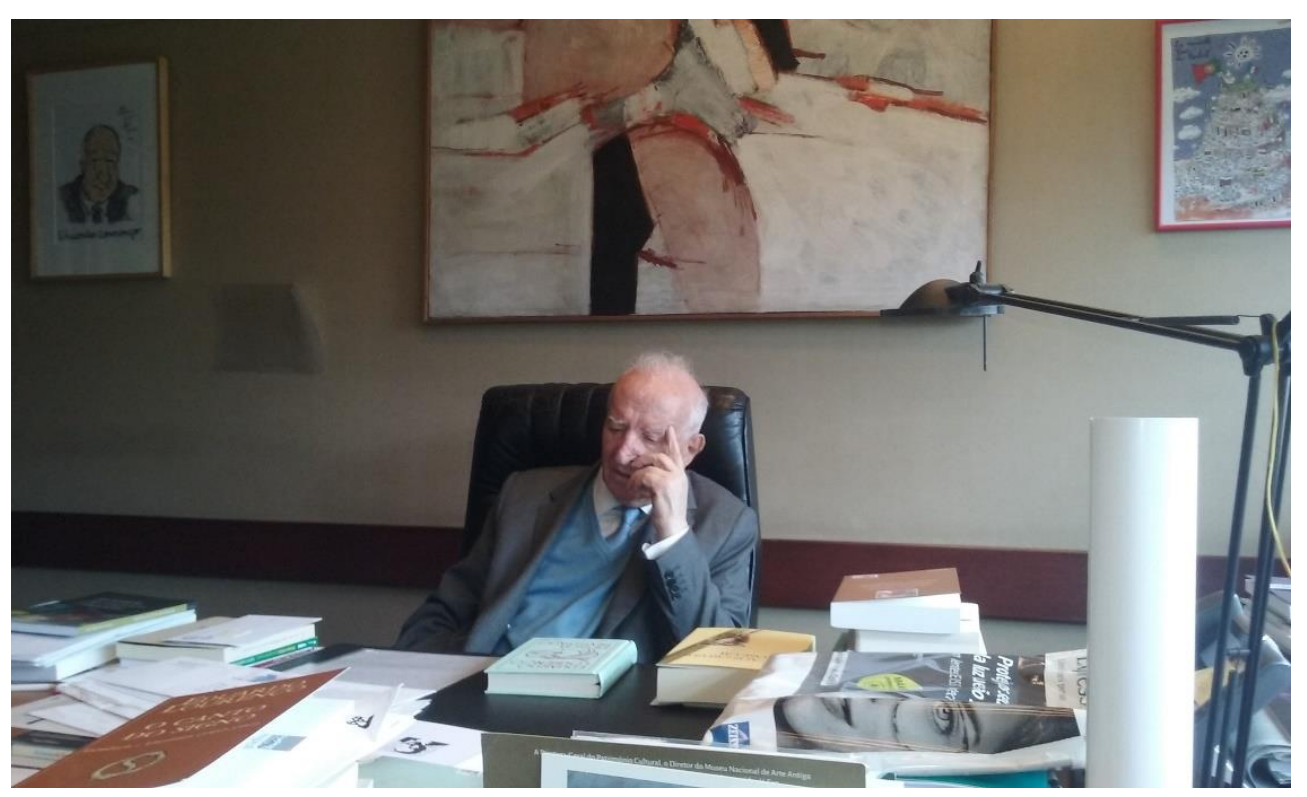

PP: Por isso o Professor utiliza como epígrafe uma afirmação de António Mora: “O que é preciso é compenetrarmo-nos de que, na leitura de todos os livros, devemos seguir o autor e não querer que ele nos siga."

EL: Exatamente. E além de ser um grande poeta, ele é um grande comentador de si próprio, a sua obra é uma poética contínua. De maneira que ninguém pode ter a pretensão de descobrir mistérios ou horizontes que ele próprio não tenha realmente apontado ou frequentado, o que é ainda mais extraordinário. E acho que Fernando Pessoa é uma propriedade, entre aspas ou sem aspas, da Cultura Portuguesa na sua originalidade. Acho que é um dos poetas do século XX mais conhecidos. Pode parecer pretensão portuguesa, mas não creio. As traduções, que correm o mundo fora, o mostram. É difícil para um país como Portugal que alguém seja visível a nível internacional de maneira duradoura. Nós temos alguns, mas o caso dele... pode ser injusto para outros poetas inclusive o Sá-Carneiro. Acho que MSC é um poeta que merece figurar como se fossem dois irmãos romanos da época heroica: um ao lado do outro. E de resto o Pessoa não queria estar no outro lado sem a 
companhia do Mário de Sá-Carneiro. Acho que foi um par de amigos, gênios um e outro, diferentes.

FR: Mas ao exegeta é também devida esta projeção internacional, o Professor também lecionou na Universidade quando esteve no Brasil onde conheceu Adolfo Casais Monteiro, segundo o qual Pessoa oferece ao leitor moderno «uma longa explicação do homem consigo mesmo».

EL: ACM merece uma referência especial não só pelo fato de que foi ele quem teve a ideia de pedir a Pessoa que explicasse um pouco esta coisa extraordinária da sua multiplicação em poetas - e nós temos as cartas. Versão única que existe e é coerente, pois interessava ao próprio Pessoa explicar com a lucidez de que era capaz, a sua e de mais ninguém, toda essa espécie de jogo do poeta consigo mesmo, do seu imaginário consigo mesmo. De maneira que ACM é dos exegetas que merece ser sempre nomeado. Outros foram mais biógrafos como João Gaspar Simões, Jacinto do Prado Coelho entre outros exegetas inclusive brasileiros.

FR: A crítica estilístico-literária por Prado Coelho.

EL: Primeiro o pai - Jacinto do Prado Coelho - e depois o filho - Eduardo Prado Coelho - que também passou a ter muita importância para mim e que é a pessoa mais inteligente que encontrei na minha vida. Cultura literária comparada a poucas quer em língua portuguesa quer em outras línguas. De certa altura, como se a família Prado Coelho tivesse estado com Fernando Pessoa. Fernando Pessoa era aquela casa, ainda bem.

PP: Mas a Casais Monteiro... a via heterodoxa...

EL: Naquele tempo, Adolfo Casais Monteiro foi dos primeiros a contribuir para a mundividência internacional de Pessoa, para além dos franceses, de Octavio Paz, de Leyla Perrone Moisés e outros. Na verdade ele era quem se aproximava mais do meu próprio percurso institucional oriundo da filosofia, era mais apto para se impressionar com aquelas fulgurações do nosso poeta.

FR: E João Gaspar Simões, que era um homem da Presença, representava uma outra perspectiva literária. 


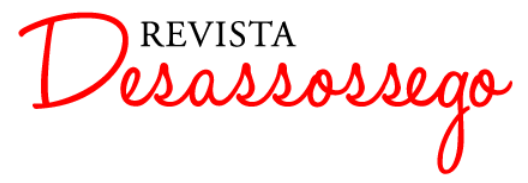

DESASSOSSEGO 20 | DEZ/2018 | ISSN 2175-3180

DOI: http://dx.doi.org/10.11606/issn.2175-3180.v10i20p163-178

EL: Esse tipo de leitura psicologista, traumas de infância, uma grelha de explicações que remetem para uma interpretação psicológica da literatura e da cultura; e parece-me ter sido mais ou menos isso o que separou Pessoa da Geração da Presença.

FR: O discurso do crítico enaltecendo a genialidade do poeta, almejando revelar-nos o valor de «O silêncio anterior à palavra» próprio da modernidade como assinala em PR?

EL: E espero sobretudo ter contribuído para que as pessoas que me lêem pensem que aquilo que digo sobre Pessoa tenha alguma coerência ou algum sentido, sobretudo por FP não precisar do nosso assentimento. Ele é o que é, quem o lê é que fica como vacinado ou iluminado para sempre.

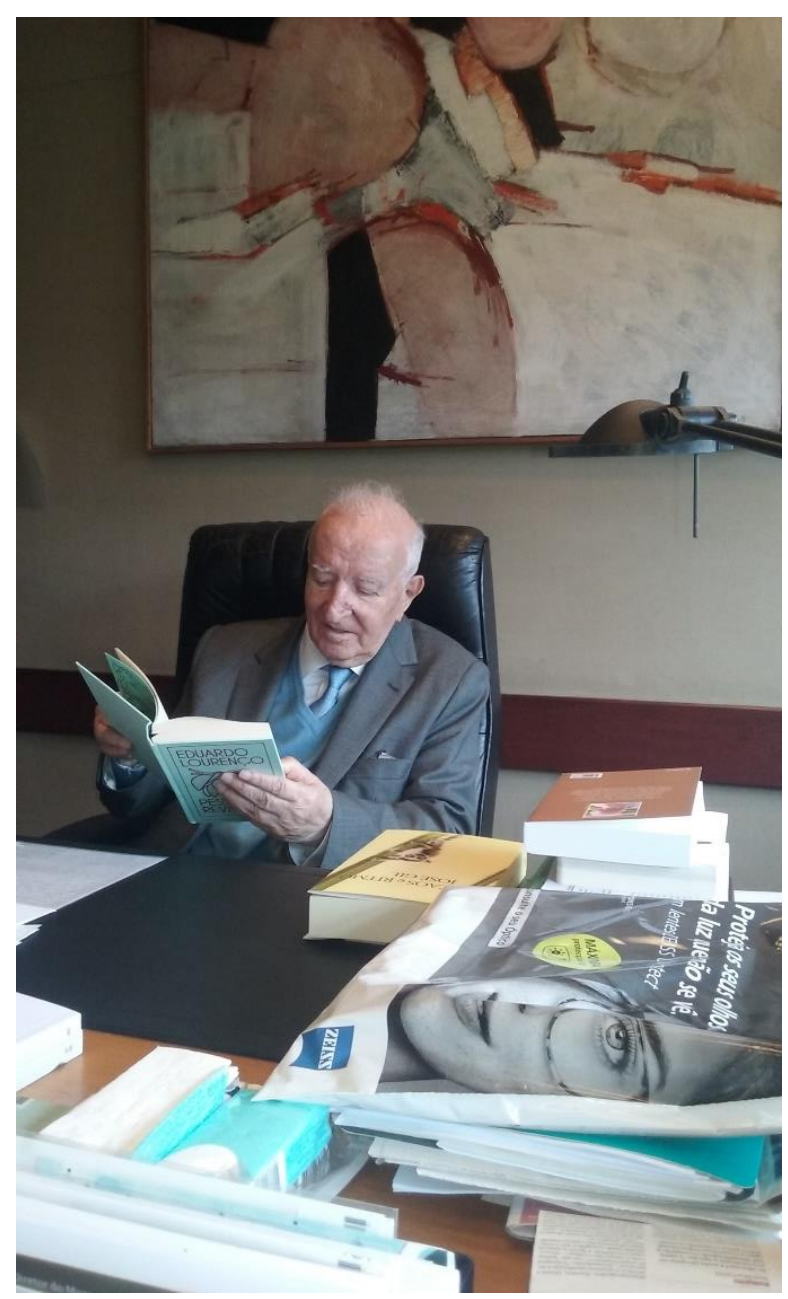

PP: Numa entrevista a Maria Ivone Ornelas de Andrade, o Professor se declara um "leitor osmótico" e faz questão de distinguir os tempos diferentes da paixão literária (tempo da 
ofuscação) e o da paixão filosófica (tempo da abertura). Me lembrei do Pessoa que dizia ser um poeta inspirado pela filosofia e não um filósofo inspirado pela poesia. E o Sr.?

EL: Nem uma coisa nem outra. Eu fui definido no princípio como sendo um ensaísta. Basta. Ensaísta é uma coisa vaga, serve para tudo. De maneira que também posso caber aí.

PP: E como ensaísta, o Sr. também pondera constantemente acerca da importância da cultura inglesa na construção da obra pessoana?

EL: Tenho a impressão que o Pessoa se construiu a si próprio enquanto menino que fez a sua aprendizagem escolar lá fora, em língua inglesa. Alguém que é inexplicável sem esta espécie de convívio diário, constante, com a obra de Shakespeare. Essa foi de fato a especificidade desse menino que estava em outro planeta, não um planeta geográfico, mas lírico, poético, planeta chamado dramático, sobretudo chamado Shakespeare. E naquela altura em Portugal havia talvez uma pessoa ou duas, professores universitários, que conheciam bem Shakespeare, mas que não eram escritores, não eram propriamente poetas, tirando, posteriormente, Jorge de Sena.

FR: A distanciação — detachment — ocorre sob influência de Shakespeare...

EL: Bom... isso é uma coisa que podia não ter acontecido. Não sei tão bem se não teria tido muita importância o fato de tal especificidade — através de Shakespeare e através da literatura inglesa, pois conhecia muito bem os românticos ingleses - estar no fundo a ser penetrada dos valores, das visões de uma cultura protestante que em termos de ordem religiosa era diferente daquela que é nossa. Penso que esta espécie de distanciação que ele tem em relação ao cristismo vem numa leitura vagamente ou realmente protestante dessa crença, dessa versão do cristianismo.

FR: Uma espécie de nostalgia: «a nostalgia da realidade das coisas» (Octavio Paz, 1988)

EL: Ora bem... no século XIX há uma espécie de nostalgia, em certas culturas, do modelo grego e dessa nostalgia ele fez mais do que uma nostalgia, fez o que seria necessário: que nos repaganizássemos no sentido de estarmos próximos do modelo grego, quer dizer, uma espécie de aceitação do poema enquanto tal. Poema como sendo ele próprio sem ter necessidade de se justificar. O poema é aquilo que é: ilumina, abre; aquilo que permite às pessoas terem uma visão das coisas. Não é uma visão banal das coisas, senão não era poeta. 
Ele escolheu Ricardo Reis, foi ele que de algum modo encomendou o encargo de ser uma versão do paganismo para a Modernidade que era do tempo dele.

PP: O culto da Grécia Antiga... a Cultura Pagã... Podemos aproximar a poética de Sophia de Mello Andresen à poética de Caeiro?

EL: Sim. A Sophia tem esta paixão da Grécia também. Paixão genuína, e nisso há qualquer coisa comum entre os dois. Mas no lirismo de Sophia não há segundas intenções. Segundo o modelo que herdamos da beleza enquanto tal, da luminosidade do pensamento, tudo isso são coisas que o autor do Fausto, sobretudo nesse livro, apresenta como objetos de remeditação, de reconstrução, de contestação até.

FR: Pessoa racionaliza, a sua sinceridade é intelectual... «um deus no sentido pagão (...) não é mais que a inteligência que um ente tem de si próprio» (in Presença, n. ${ }^{\circ}$ 5, 1927)

EL: Fernando Pessoa pode ao mesmo tempo dizer isso e o seu contrário sem que isso signifique para ele contradição. Joga com as possibilidades da imaginação até ao fim, até onde pode. Nunca saberemos o que ele disse, o que ele diz, o que continuará a dizer. Enfim para mim foi um fascínio, estou certo que nunca mais terminará.

FR: Sophia apresenta esse amor pela cultura helênica enquanto que Pessoa apresenta o modelo pagão como alternativa à sociedade velha que é a sociedade da Europa, não será?

EL: Não sei se será isso. Eu penso que ela de fato também quis pertencer ao mundo grego propriamente dito, de maneira que os dois estão próximos, e muito fascinados por este mundo. Em parte, o Jorge de Sena mais tarde também.

PP: ... mas a linguagem na poesia de Sophia é muito concreta, é uma linguagem muito próxima da coisa.

EL: Sim, sim... ela não faz jogos.

PP: E por um lado me lembra um poema do Guardador de Rebanhos: "Procuro encostar as palavras à ideia / e não precisar de um corredor / do pensamento para as palavras".

EL: Essa problemática não é uma problemática da Sophia. Ela escreve como se ninguém antes dela tivesse feito versos. Como se quisesse escrever os versos que nunca ninguém escreveu, unicamente com o fascínio dessa expressão que é diferente da expressão da linguagem a que nós chamamos Poesia. É uma poetisa nata. Fernando Pessoa também, mas 
teve uma espécie de percurso através de uma cultura que é das culturas mais complexas da Europa.

FR: Mas aí Pessoa cultiva essa atitude, como o Professor Eduardo Lourenço melhor que ninguém referiu, essa distanciação e o tal detachment, e, perseguindo essa aproximação de Pessoa a Shakespeare...

EL: Não conheço nenhum poema que tenha essa complexidade fantástica como o Fausto, neste poema estão todas as questões mais tradicionais da filosofia, do pensamento europeu, etc. Tudo é interrogado: as coisas mais fundas e as maiores audácias. No fundo Pessoa diz e até pensa que é deus a passar para o humano. É uma coisa delirante, de loucura quase poética. Mas é um desafio radical. Além disso é a coisa menos estudada em Fernando Pessoa, essa frequência que ele teve da literatura esotérica. Ao tempo foi a coisa que mais levou a sério enquanto poesia de outros. Ora isso de fato escapa-nos, são já matemáticas mitificadas, elípticas de algum modo, e não sabemos exatamente onde ele quis chegar. Mas é isso que nos encanta na maioria das vezes, é o fato de que por mais que o leiamos não conseguimos saber exatamente o que ele está a dizer, e isso fascina-nos porque ele não decifra o mistério, ele aumenta o mistério.

PP: "O único mistério é haver quem pense no mistério"

EL: Mistério que não é o mistério literário, é o enigma da vida enquanto tal. Portanto realmente ele pode ser reclamado como filósofo. Não conheço ninguém que tenha feito coisa mais extraordinária, inquietante, uma espécie de audácia quase no limite da loucura. De resto, ainda na sua juventude chegou a pedir uma espécie de testemunho sobre a sua condição de louco, para estar certo de que se fosse louco era um gênio verdadeiro. Bom, isto é um jogo, mas uma pessoa que quer simular a loucura já tem alguma tendência. Enfim, louco era, mas todos gostariam de ser loucos como ele. 


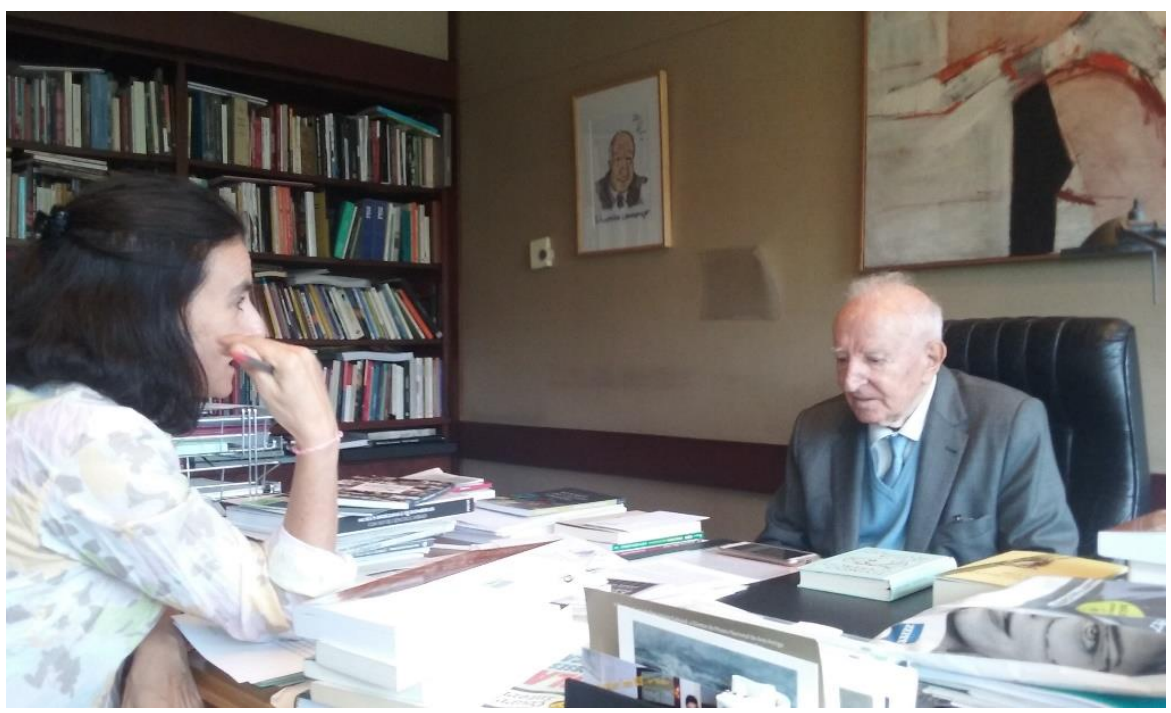

FR: E o jogo persiste. Whitman evidente em Álvaro de Campos...

EL: ... como ele próprio diz.

FR: Mas o Professor em PR chama-nos já a atenção: Whitman não está menos presente, ainda que discretamente, na objetividade absoluta de Caeiro cujos poemas são «um refúgio e uma libertação» seminais de onde vão emergir outros eus de Pessoa.

EL: É curioso ter acontecido em certa altura esse encontro que eu chamo de virtual ou real — trata-se de literatura. Chamou-me muita atenção o conhecimento de Walt Whitman (18191892) que era muito recente na Europa, apesar de ser antigo na América. O encontro de Whitman foi explícito mais ou menos em 1913. Quase em cima da hora, Fernando Pessoa já estava a reclamar-se de Walt Whitman. E naquela altura Whitman não tinha praticamente leitores em Portugal, inclusive o próprio Mário de Sá-Carneiro e seus companheiros daquela época, porque não tinham cultura inglesa. Agora essa escolha provavelmente não foi uma escolha pura, literária, propriamente dita. Penso que ele também foi muito fascinado pela figura de Walt Whitman e do caso W.W. pelo fato de ser um autor muito pouco aceite por uma parte da sociedade americana.

PP: Por conta da homossexualidade?

EL: Aqui para nós, desculpe a expressão, “ele estava-se nas tintas", ele tinha assumido. Era o cantor das coisas da América, mas também não tenho conhecimento suficiente de W.W. para me embrenhar neste gênero de considerações.

PP: Poesia e Eros. O que nos remete também para a relação de Pessoa com Ofélia? 
EL: Em Portugal nessa altura ninguém fazia realmente a passagem de uma coisa para a outra; depois começou a falar-se nisso naquela famosa biografia do JGS, no ensaio intitulado " $\mathrm{O}$ Enigma de Eros", creio eu. Coisas que se repercutiam a propósito da nova ciência: a psicanálise. É sempre um problema complicado. E depois há o problema propriamente do seu caso com a famosa Ofélia, o que é engraçado, porque não é muito diferente, embora não saiba se pela mesma razão, do caso de Kierkegaard e da sua namorada — também um grande amor. Penso que teve muita importância para essa pequena paixão, o fato dessa companheira de escritório chamar-se Ofélia.

PP: Escolheu a dedo a personagem shakespeariana.

EL: Era uma tentação muito grande ele passar realmente a chamar-se Hamlet.

PP: Uma tentação literária.

EL: Uma tentação, que não era sempre. Portanto ele podia ser ou muito literato ou inocente. PP: Se nas cartas a Ofélia há ali qualquer coisa de erótico, na poesia dos heterônimos esse erotismo quase inexiste. Em PR o Sr. fala da sexualidade branca: no Caeiro não há, no Reis há apenas idealidade e no Campos o erotismo aparece transfigurado no seu imaginário. E a poesia do ortônimo?

EL: A única coisa propriamente erótica que há nele é quando veio aquele mago Aleister Crowley acompanhado por uma Alemã que devia ser suntuosa — não sei, não a conheci, nunca a vi, nem sei quem é; mas sei que, a esse propósito, Pessoa escreveu uns versos que são uns versos banais, ou não banais, de heterossexualidade. Portanto está a falar de uma mulher que se ama, que se adora, se idealiza, mas o resto não.

PP: Se Caeiro é a saúde fictícia, Reis um convalescente fictício, qual a doença de que Campos padece?

EL: É uma boa questão!

FR: Será o frenesi, essa «tensão nervosa» (Pessoa), neurastenia evidente no querer agarrar todos os momentos da sociedade hiperindustrial, moderna, prenhe deste século XXI, já a crescer?

EL: Eu creio que isso tudo é muito literário. 
FR: «Nada disso estheticamente importa», dirá Pessoa referindo-se ao carácter «mórbido ou estranho» do pensamento no artista.

EL: Creio que não teve essa vertigem diante da Modernidade, mais a mais na Modernidade em termos portugueses. Nós não tínhamos essas fábricas, essas coisas assim, esse imaginário de uma civilização que na altura era a civilização que estava a abrir caminhos novos de visão das coisas reais, da transformação do mundo tal qual ele via nesse momento. No fundo sentese que está mais perto de Reis, civilismo suave, o campo, ao mesmo tempo o retiro.

[E. Lourenço lendo de um trecho do livro Pessoa Revisitado com pequenos comentários]

EL: «Numa passagem conhecida da carta de 25 de Fevereiro de 1933 [EL: "Era muito tarde, em 33 já estava a dois anos da morte”] a Gaspar Simões, sem nenhum daqueles laivos de humor que nele tudo remetem para a ambiguidade, Pessoa não hesitou em escrever: 'Teria eu assim o prazer de serem vv. que apresentassem o melhor que eu tenho feito - obra que, ainda que eu escrevesse outra Ilíada [EL: “Não passa por menos: megalômano!”], não poderia, num certo sentido íntimo, jamais igualar, porque procede de um grau e tipo de inspiração [EL: "Começa ele com os mistérios"] (passe a palavra, por aqui exata) que excede o que eu racionalmente poderia gerar dentro de mim, o que nunca é verdade das Ilíadas.' [EL: “Isto é o máximo!’' Não há aqui a mais pequena possibilidade de situar Caeiro em paragens conhecidas. Mas a verdade, ainda que sob a forma de 'lapso' por contiguidade, irrompe na passagem célebre do inevitável Álvaro de Campos (aquele que poderia referir-se com mais filial naturalidade a Whitman) acerca das 'três verdadeiras manifestações de arte nãoaristotélica' [EL: 'E eu andava julgando que descobri a pólvora — quando havia declarações expressas e eu não dei por elas!’]: ‘A primeira está nos assombrosos poemas de Walt Whitman [EL: “Que é que se quer mais?”]; a segunda está nos poemas mais que assombrosos do meu mestre Caeiro [EL: "Emenda o outro, ou leva-o até à sua expressão mais exacerbada"]; a terceira está nas duas odes - Ode Triunfal e a Ode Marítima — que publiquei no Orpheu. Não pergunto se isto é imodéstia. Afirmo que é verdade.' Eis Caeiro situado exatamente pelo seu autor, sem o querer, ou querendo-o para outros fins, onde realmente está e existe: entre os 'assombrosos' poemas de Whitman e os admiráveis de Campos, filho incógnito de uns e pai confessado dos outros. O gesto de o pôr à parte, e acima, não chega, bem pelo contrário, para minimizar o entre onde, por instinto, Pessoa-Campos o colocou. E 
menos ainda o gesto de envolver o 'Mestre' na sombra que também nele há, mas não tão forte que tenha criado a noite à sua volta, de Cesário Verde, à memória de quem pensou dedicar os poemas-Caeiro.”(pp. 89-90)

EL: E aqui há o jogo com o imaginário poético da época, sociedade do século XIX e princípios do século XX. É novidade vinda destes encontros, como eram conhecidos dos nossos poetas desta época. O que está escrito, está escrito, e eu não posso emendar! Acabouse!

FR: Este livro contribui para que esta nova geração de estudantes e de novos professores universitários brasileiros recuperem em Pessoa a dimensão da globalidade do homem enquanto «Homem Completo», como definiu no Ultimatum?

EL: A gente escreve sempre na convicção dessas coisas que são desejáveis e agora nunca está certa de alcançar aquilo para que escreveu realmente. No meu caso, não tenho leituras imediatas daquilo que faço, é um pouco o que os deuses me oferecem.

FR - Comunga da humildade dos grandes?

EL: Não, dos pequenos. Têm direito à humildade, os grandes não precisam de um complemento da vaidade.

FR: O Professor é conselheiro de Estado. O nosso Presidente da República Marcelo Rebelo de Sousa convidou-o; como também a outro Professor, cujo respeito e amizade partilhamos, o anterior Presidente da Academia das Ciências, Professor Adriano Moreira. Ambos são Conselheiros de Estado, anciãos para nós importantes. E o Sr. não é poeta, certo? Foi o que disse?

EL: Sim, exato.

FR: Está bem, compreendo. É Filósofo, também compreendo.

EL: Nunca me declarei filósofo, é uma das maiores ambições que uma pessoa pode ter, nunca me vou alojar a essa casa.

FR: Um filósofo partilhando o Conselho de que o Presidente Rebelo de Sousa dispõe para ser ainda mais bem acolhido na sociedade, quer portuguesa quer internacional, tal como recentemente aconteceu com o Presidente dos Estados Unidos da América, D. Trump. 
Também esse é um modelo perfilhado por Pessoa: o da «República Nova». Qual o papel da filosofia e de um homem que escreveu poesia ainda que em primícias juvenis?

EL: Uma vez, não sei em que circunstância, foi a seguir ao 25 de Abril, houve uma espécie de embaixada que os Portugueses levaram a Paris, como se houvesse a obrigação, cada vez que há uma coisa importante, de a gente prestar vassalagem à cidade Luz. Já tinha havido uma coisa em relação à Espanha, uma comemoração, mas que não tinha tido grande eco porque o relacionamento das pátrias é muito singular. E realmente a França e a Espanha foram nações que se combateram a sério durante certos períodos famosos da história de cada um destes povos. Os franceses invadiram a Península Ibérica, Portugal compreendido. Nós perdoamos aos franceses, perdoamos-lhes tudo, os espanhóis menos, porque o Goya não deixa.

Dos autores portugueses que têm estado lá fora, ou dos que estão lá fora, muitos deles, como leitores entre outras profissões, contribuíram para que Portugal tenha algum reconhecimento em certos países da Europa, uns mais, outros menos, depende, não é? Mas os portugueses não têm de que se queixar, de pensar que os outros estão mais presentes em tudo — à exceção dos grandes dos grandes que não precisam desta espécie de estímulo suplementar. Pessoa, acho, que passou essa fase masoquista, excessiva, em que nós éramos os últimos, que somos os últimos, que não somos conhecidos, ninguém nos conhece, ninguém nos lê.

FR: "Coitadinho do tiraninho/ (...) Bebe a verdade e a liberdade / E com tal agrado / Que já começaram / a escassear no mercado...”

EL: Não é verdade sobretudo ao nível da cultura mais eficaz que é a cultura da juventude atual. Portugal transformou-se no Menino Jesus dos espetáculos. Não sei se é a melhor escolha, mas enfim sempre é uma coisa celeste. As pessoas vêm aqui a Portugal... é como quem vai a... não sei, como se ia a Paris antigamente no século XIX, no século XX... como dizia a mãe de Napoleão, pourvu que ça dure. Porque Portugal não pode estar sempre em festa, ou está de lágrimas ou está de festa. Não é como o Brasil, que está sempre na cantiga, de samba, de dança, e é um país positivo. Portugal esforça-se por ser um país positivo, mas agora está numa fase, numa onda talvez, até por, entre outras coisas, termos um presidente que de fato é a maior imagem que Portugal pode ter neste momento de si próprio em matéria de ordem política e cultural, quer até das duas coisas ao mesmo tempo. 
FR: Eduardo Prado Coelho em 1975, depois do 25 de Abril, dirigia uma delegação cultural em Paris para a qual convocou o Prof. Eduardo Lourenço que foi apresentado: «E. Lourenço não é poeta, mas é Amigo dos poetas.» Filósofo, homem da cultura. Amigo dos poetas. O modelo de Pessoa: o culto da elite que humildemente oferece a sua visão presbíope para o país que quer que cresça e se projete internacionalmente. Tal como o Embaixador José Pedro Cutileiro refere: a Portugal o ganho conferido pelo destaque, e a fortiori liderança em Organismos Internacionais.

\section{EL: Incrível!}

FR: Mário Centeno, Presidente do Eurogrupo em Bruxelas; António Guterres, Secretário Geral das Nações Unidas; Vitor Constâncio, Vice-presidente do Banco Central Europeu, entre outros.

EL: Talvez o mais surpreendente de tudo isso, mas enfim a nossa ligação, já esquecemos isso, como os franceses esqueceram. Os franceses se apresentavam a si mesmos como uma espécie de embaixadores do religioso em terras pagãs. Nós nunca tivemos essa pretensão, porque nós éramos católicos sem mais problemas. Neste momento, uma das coisas mais interessantes é a nomeação do Padre José Tolentino Mendonça, também poeta, para, um cargo extraordinário no Vaticano, guardião da biblioteca da Santa Sé, o que não é uma honraria banal. Ele é ainda jovem.

FR: Nomeado (26 Junho 2018) pelo Papa Francisco para Arquivista do Arquivo Secreto do Vaticano e Bibliotecário da Santa Sé...

EL: Nós há muito tempo não tínhamos nada assim, sobretudo para um país que tem uma tradição católica ininterrupta até hoje. Mesmo para os que não são católicos, o país é católico. Como o Brasil, por mais eclético que seja, as pessoas são normalmente religiosas nos seus mitos, nas suas coisas, esses e outros, contrários até, mas enfim... Estive na BAHIA, sei o que eram aqueles ritos, Iemanjá, tudo aquilo, tudo misturado com o cristianismo, isto é uma herança portuguesa.

PP: Um mundo de surpresas...

EL: É assim, estamos sobretudo em um mundo curioso. Ainda hoje fui a este Colóquio na Universidade Nova de Lisboa e um sociólogo chamado Alfredo Wagner Berno de Almeida esteve a falar do momento atual que está a viver o mundo, muito perturbado, sem se saber 
exatamente qual a nação que esteja a liderar. Os Estados Unidos foram sempre otimistas, naturalmente, e continuam a mandar de resto, embora depois finjam que não. Deve ser a sua melhor habilidade neste momento. Mas o vosso Professor e Antropólogo Social estava muito preocupado com este problema da indiferença, de uma certa despreocupação sobre o destino que a humanidade se reserva a si mesma nesta fase em que está. Uns que realmente passaram situações terríveis ou catastróficas e conseguiram alcançar uma situação enfim aceitável e outros que estão, de fato, em situações precárias, coisas terríveis, crimes sempre nestes estados mais antigos, mais carentes. Portugal neste momento não está pior que a Espanha. A França está melhor, porque a França sempre esteve melhor. A Inglaterra é a mesma coisa: do que é que se queixariam quando mandaram durante séculos no mundo, quase sem intervalos? Engraçado é esta coisa da Rainha. Neste momento passam umas imagens na televisão, os ingleses preparando o enterro da Rainha que está viva...

PP: Viva e forte.

EL: Realmente aquilo é uma coisa que até arrepia. Ela sempre com seu chapéu e aquela indumentária toda e eles a preparem uma grande coisa, uma "Coisa" digna para quando ela morrer. E não perguntam nada. Ela deve estar de acordo, com certeza, aquilo lá é uma teatrada que nem Shakespeare. Shakespeare do pior. Os países, às vezes, têm coisas extraordinárias... cada um de nós a preparar o cadafalso! A Inglaterra tem cada coisa, cada surpresa, mas sempre grandiosa. A Inglaterra é bem capaz de fazer isso, a França já não tem capacidade para isso; nem nenhum país europeu; nem a América, a América nunca teve.

FR: O Brasil dentro da sua cultura de espontaneidade e dentro da vivacidade da sua cultura autóctone também não tem essa grandeza: a do seus grandes poetas?

EL: Mas tem, tiveram sempre. Esta veia é comum nos dois lados do Atlântico.

FR: Portugal-Brasil da Língua Portuguesa: «a minha pátria é a língua portuguesa», Pessoa dizia isso no sentido político, não só no sentido poético.

EL: A gente nem sabe o que que ele queria dizer com isso, e pouco importa. Era a melhor coisa que ele tinha a dizer para alguém que era de língua inglesa, dizer que a minha pátria é a Língua Portuguesa, porque ele sentia que era um menino que tinha duas línguas.

\section{Ficha Técnica:}




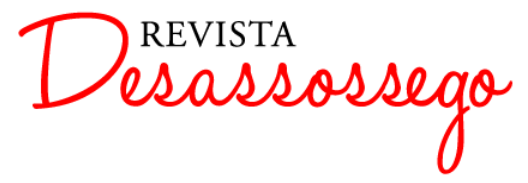

Concepção e Entrevista:

Paola Poma - Universidade de São Paulo- Faculdade de Filosofia, Letras e Ciências Humanas - Brasil.

Fernando Ribeiro - Universidade Nova de Lisboa-Faculdade de Ciências Sociais e Humanas - Portugal.

Transcrição: Paola Poma

Edição: Paola PomaC -PP; Fernando Ribeiro@-FR

Fotos: seleção Paola Poma e Fernando Ribeiro.

Fotos de Eduardo Lourenço-EL - e Eduardo Lourenço -Paola Poma: copyright: Fernando RibeiroC.

Entrevista a Professor Eduardo Lourenço realizada em seu Gabinete na Fundação Calouste Gulbenkian Lisboa-Portugal a 5 de Julho 2018 previamente preparada com E.L. a 28 Junho 2018.

Agradecimentos: - Dr ${ }^{a}$ Susana Major- secretária de Professor E. Lourenço em FCG.

- Dr José Ernesto Lopes- Medialab UNL-FCSH. 